\title{
Drawing together: making marginal futures visible through collaborative comic creation (CCC)
}

\author{
Johannes Theodor Aalders ${ }^{1}$, Anne Moraa $^{2}$, Naddya Adhiambo Oluoch-Olunya ${ }^{3}$, and Daniel Muli ${ }^{4}$ \\ ${ }^{1}$ School of Global Studies, Gothenburg University, Göteborg, 40530, Sweden \\ ${ }^{2}$ LAM Sisterhood, Nairobi, 00100, Kenya \\ ${ }^{3}$ Sunflower Pictures, Nairobi, 00100, Kenya \\ ${ }^{4}$ independent illustrator: Nairobi, 00100, Kenya \\ Correspondence: Johannes Theodor Aalders (theodor.aalders@gu.se)
}

Received: 30 March 2020 - Revised: 6 September 2020 - Accepted: 22 September 2020 - Published: 2 December 2020

\begin{abstract}
The article introduces collaborative comic creation (CCC) as a methodological tool. The central question it addresses is how marginalised imaginations of futures can be made visible in the context of the planned Lamu Port-South Sudan-Ethiopia-Transport (LAPSSET) in Kenya. The question assumes that infrastructure projects such as the LAPSSET corridor inscribe not only particular ways of moving into a landscape but also one specific temporality that marginalises other future-making practices. The paper participates in the ongoing debate about how imagined futures and future-making practices can be appreciated and analysed methodologically. It thus contributes to the literature on geographies of the future by drawing together conceptual insights from anthropology, infrastructure studies, and critical cartography. Based on these different approaches, the paper proposes to regard future-making practices not only in relation to contentious timelines but also in terms of lines made by moving and drawing on landscapes and surfaces. Using a review of existing social foresight methods as a basis, we describe the practical implementation of CCC. Subsequently, the analysis of one collaboratively produced comic illustrates how the method can help to visualise ambivalent and uncertain imaginations of different futures that oppose the unitary vision of modernity produced by dominant infrastructural visions of a single future. We conclude by reflecting on possible ways of developing the method further.
\end{abstract}

\section{Introduction}

"Whose imaginations are employed?" asks MüllerMahn (2019:2) in the context of the production of African futures through mega-infrastructure projects. He argues that "corridor masterplans" (Müller-Mahn, 2019:2) inscribe not only particular ways of moving into a landscape but also specific ways of imagining futures, creating a particular dreamscape of modernity (Jasanoff and Kim, 2015). In the process, they override and thus conceal contrary mobilities and imaginations, while presenting the masterplan through maps, documents, and digital renderings as universal and inevitable. Taking the question of whose imaginations are employed seriously implies engaging with those imaginations that are not employed - with invisible, marginal futures. The central question this article addresses is how marginalised futures can be made visible when corridor masterplans or other dominant visions occlude them, such as the planned Lamu Port-South Sudan-Ethiopia-Transport (LAPSSET) in Kenya. Using future-making practices in relation to the LAPSSET corridor as a case study, this article engages with this question in two ways: (a) conceptually it makes the argument for approaching marginal futures through attention to movements, historicities, and images that do not align with infrastructural masterplans, and (b) methodologically it suggests making marginal futures visible through the collaborative creation of comic strips.

This paper contributes to the growing literature on geographies of the future by drawing together conceptual insights from anthropology, infrastructure studies, and critical cartography, as well as post-foundational discussions of the pure and the historic event. It furthermore engages with the fun- 
damental epistemological conundrum that all scientific engagements with the future face - how is it possible to know anything about something that is by definition not present? and sketches the outlines of a concrete approach to answer it. We focus on both the advantages and potential this approach has and the ways in which we have failed to implement it successfully.

We start with an overview of different conceptualisations of the future, distilling a theoretical framework that focusses on three different kinds of lines: lines through space, timelines, and lastly those drawn on paper. The subsequent section reviews different existing approaches to researching futures, developing collaborative comic creation (CCC) as a synthesis of these "social foresight methods". We subsequently summarise the practical implementation and challenges of CCC in the context of a study on an infrastructure project in Kenya. Lastly, we illustrate the possible results of CCC through an example of "critical carto(on)graphy" and conclude with some deliberations on the method's validity and transferability to different contexts.

\subsection{Conceptual outline}

In order to engage with the future at all, it is necessary to depart from the notion that the future is currently not present, as paradoxical as this may seem at first glance. Appadurai (2013) suggests regarding the future as a "cultural fact", as something that is actively produced, instead of passively awaited. He distinguishes different practices of futuremaking, such as aspiring, imagining, and anticipating (Appadurai, 2013:286), which he uses to understand the future "not as a technical or neutral space" (Appadurai, 2013:286287) but as emotionally charged and political in the sense that the "capacity to aspire" (Appadurai, 2004) is not distributed equally. The understanding of futurity in this article therefore disagrees to some extent with John Mbiti's writing on the "African concept of time" (Mbiti, 1990:16f.), in which he claims that traditional concepts of time in Africa know "virtually no future" (Mbiti, 1990:16, emphasis in original). We do however recognise that a linear conceptualisation of time is neither universal nor inevitable and that dominant understandings of temporality have overwritten alternative, now marginalised, ways of imagining time and the future.

In order to address futures as cultural facts, this article is primarily concerned with the inscription of lines (see Ingold, 2007). This most general and rather abstract topic encompasses a wide range of subject areas: the charting of imagined landscapes on a map and the subsequent re-tracing of these maps as infrastructural lines in landscapes - lines drawn in tarmac following lines drawn in ink. It encompasses the sketching of memories and expectations into storylines and the ways in which history is inscribed into biographies. This implies the drawing of timelines; the conjuring of relations between past, present, and future; and the recognition of how existing pathways channel these mem-

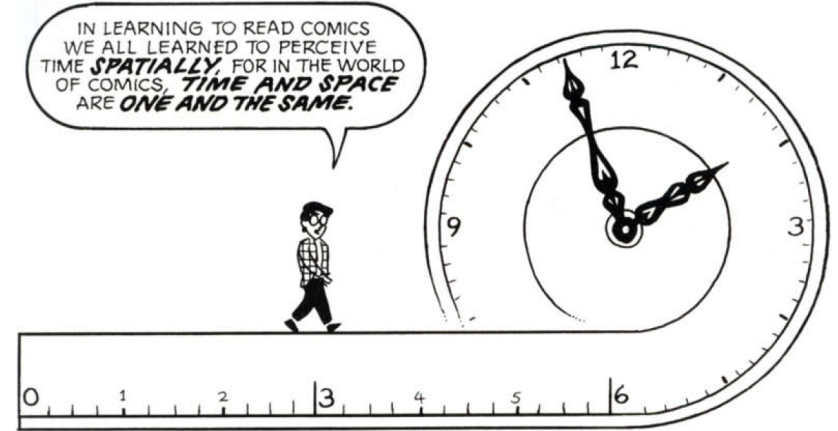

Figure 1. Panel in Scott McCloud's Understanding Comics: The Invisible Art (McCloud, 1994:100).

ories and expectations through space. This recognition of lines created by movements through landscapes invites geography into the discussion of future-making practices. As Massey (2005:119) maintains, "movement, and the making of relations, take/make time" (see also Cresswell, 2004:4). In comic books this relation between - or rather the convergence of - space and time is particularly obvious. Time, on the page of a comic book, is marked by the movement between individual panels - "in the world of comics, time and space are the same", as McCloud (1993:100) puts it (see Fig. 1).

To address all of these aspects of line inscriptions, this article draws from three distinct but related academic traditions that attend to the line in different ways. The first and most explicit as well as comprehensive recognition of the line is the extensive work of Ingold (2007, 2011a, b) on the anthropology of the line, in which he discusses "walking, weaving, observing, singing, storytelling, drawing and writing" (Ingold, 2007:1, 2015:53) as gestures and practices that trace and produce lines. Second, infrastructure studies are markedly relevant in terms of addressing the particularities of the LAPSSET corridor. Several authors in this area have given specific attention to how infrastructures shape memories and conjure imaginations of the future in general and modernity in particular (e.g. Appel et al., 2018; Harvey and Knox, 2012; MüllerMahn, 2019). The discussion of infrastructural temporalities is augmented by Lundborg's (2012) conceptualisation of the pure and the historic event. Lastly, critical cartography scrutinises the politics involved in mapping, not only in terms of a way to dominate marginalised people but also as a potential tool for resistance or "means of emancipation and enablement" (Corner, 2011:100). This aspect is acutely relevant in terms of the method of collaborative comic creation discussed further below.

It is widely acknowledged that the production of future imaginations is problematically entangled with imaginations of the past (Jasanoff and Kim, 2015:21). In the case of the LAPSSET corridor, or most other infrastructural development projects for that matter, this relationship is antitheti- 
cal in nature. The past is presented as something to be overcome in favour of a new, modern way of life. In this case, the "way of life" can be understood literally as the infrastructural pathways that structure the mobility of things and bodies across space. These infrastructures are synonymous with modernity itself and thus antithetical to the past they seek to overcome - as Edwards (2003:2) notes, "To be modern is to live within and by means of infrastructures". Just as mega-infrastructures tend to monopolise means of transport (Aalders, 2020), the universal vision of modernity produced by infrastructures conceals and destructs other, potentially competing, ways of drawing timelines between past, present, and future.

This understanding of temporality has a radical implication: rather than assuming that everything passively follows a natural and universal timeline, it suggests that connections between past, present, and future are actively woven into different, tentative, and potentially opposing timelines. The narrative employed by the LAPSSET Corridor Development Authority (LCDA) attempts to align the multiplicity of temporalities into one universal story about development from a dark past into a vague, yet monolithic, vision of modernity. This alignment of temporalities can be understood in terms of Lundborg's (2012) analysis of the historical and the pure event. "The pure event expresses an ambiguous process of becoming" (Lundborg, 2012:3, emphasis in original), escaping into the past and the future simultaneously. Lundborg connects this ambivalent temporality of the pure event with ambivalent movements of bodies that have neither a clear origin nor a clear destination. In contrast, the historical event attempts to bring order to these erratic movements, creating temporal borders that clearly distinguish between the "before" and "after" (Lundborg, 2012:5). These temporal borders coincide with spatial borders, making it possible for the present to "take place" (Lundborg, 2012:4). Where origins and destinations were ambiguous, the historical event creates a temporal, as well as spatial, linearity. A development corridor allows and forces the flow of oil from the wells in Lokichar to Lamu Port and thus allows and forces the progress from underdeveloped past to a modern future.

The construction of infrastructure projects implies the production of maps. Cowen (2014) regards cartographic practices as fundamental for the "political and contested production of logistics space", which in turn depends on a network of infrastructures. These mapping practices inscribe straight lines onto a map, which are then translated into the carving of straight lines into the landscape through construction work. Tim Ingold argues that through its association with "rational" Euclidean space, the straight line is synonymous with the triumph of culture over nature and with modernity itself (Ingold, 2007:152) - similarly to how infrastructural lines embody modernity. These straight lines, drawn with a ruler looking down upon an empty surface, imply a universal, detached gaze on the word. As Tim Ingold notes, "But the world that is represented in the map is one with- out inhabitants: no one is there; nothing moves or makes any sound" (Ingold, 2007:24). The imposition of straight borders on organic and fluid landscapes has been discussed extensively, particularly in relation to colonial mapping practices (e.g. Alesina et al., 2011). Not only were infrastructures instrumental in the creation of colonial empires (Headrick, 1981; van der Straeten and Hasenöhrl, 2016), but also they often continue colonial impositions of lines of transport and communication onto landscape and people (Aalders, 2020; Enns and Bersaglio, 2019).

As much as mapping practices can enable a "dictatorship by cartography" (Varadarajan, 2007), they can also be used as a contentious and potentially emancipatory practice opposing the power relations depicted and reproduced by conventional maps. Cowen calls for a queering of logistics through "countercartographies" (Cowen, 2014), and Cattoor and Perkins (2014) describe "re-cartographies", emphasising the significance of a "situated and historicized narrative approach to all mapping" (Cattoor and Perkins, 2014:166, emphasis in original). For example, psychogeographies (e.g. Debord, 1967; Sinclaire, 2018) challenge conventional mapping practices and thus reveal the ofteninvisible power relations that they depict and reproduce. Psychogeographies emerged as an artistic critique of cartographic norms but developed into a radical political intervention, through contributions from, among others, Walter Benjamin and other Marxists (Coverley, 2006:22). Similarly, the method of collaborative comic creation presented in this article is to be understood as a practice at the intersection between scientific methodology, artistic critique, and political intervention.

At this point, it is necessary to discuss the definitions of map and cartography used in this article. As a working definition, we refer to Harley and Woodward (1987), who propose an experiential understanding of a map as "graphic representations that facilitate a spatial understanding of things, concepts, conditions, processes, or events in the human world" (Harley and Woodward, 1987:xvi). This definition is experiential in that it focusses not on the content or form of the map but on the way it creates a relational "spatial understanding". Harley and Woodward (1987) furthermore emphasise the historical dimension of maps as artefacts and explicitly include "maps of imagined cosmographies" in their analysis. In contrast, conventional definitions of what constitutes a map are primarily projective, in that they are concerned with translating the position of selected features into a Euclidian coordinate system. The points and lines on a conventional map thus have locations but no histories in the sense that the movement and gestures that created these inscriptions are not present in their depiction (Ingold, 2011b). This is not to say that projective maps do not produce temporalities but that they do it clandestinely.

So how do comics fit into this conceptual discussion? How can they be understood as cartographies or countergeographies? Dittmer (2010) suggests that the pages of a 


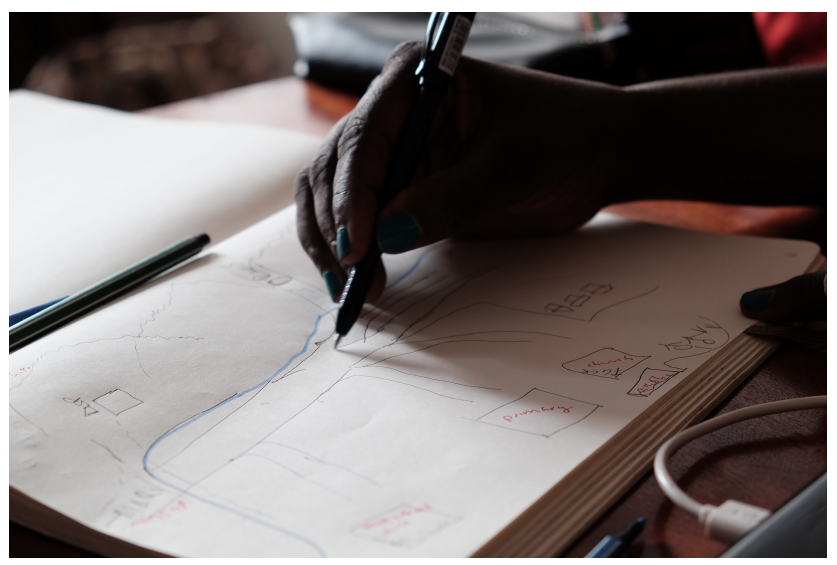

Figure 2. A workshop participant drawing a map of the future quite literally.

comic book can be read as a "micro-geography" (Dittmer, 2010:222) that defies the linear structure of conventional text or film and instead holds "possibilities of simultaneity and polyphony" (Dittmer, 2010:223). Comics thus allow for a particular heuristic, as each page can be read panel by panel or taken in all at once (Dittmer, 2010:229); they can be read as a path through a story or as "literally a map of time" (Dittmer, 2010:222). In the same vein, Peterle (2017) suggests reading comic books as emergent maps that produce "a temporary, mobile, contingent and unfinished nature" (Peterle, 2017:3). This aspect came out during the workshops as well, when the description of imagined futures often turned into the drawing of hybrid maps and landscape paintings (Fig. 2). In another workshop, participants described their anticipations primarily in terms of the impacts they foresaw for the landscape around them, thus creating a different map of time that contradicts those produced by the LAPSSET authority (Fig. 3). Yet another workshop produced a comic that incorporated maps in the panels as the protagonist, a former bush pilot, connects the aerial bird's-eye perspective with the reality on the ground (Fig. 4). Instead of a story-line, comics therefore appear as a tangle of relations as the reader's eye jumps back and forth in one panel, between image and text, and even across the page (Dittmer, 2010:230). Davies (2019) argues that entangled or "braided" geographies of comics offer a counter-geographical potential that can challenge hegemonic spatio-temporal imaginaries.

In summary, the theoretical framework outlined above brings together three different kinds of lines in the making of futures: lines through space, such as those created by cars or cows moving through a landscape; those through time, tentatively creating connections between past, present, and future; and lastly those on paper as in maps or drawings. The next section explores how the latter kind of lines can be used as a methodological entry point to explore how marginalised future-making practices can be made visible.

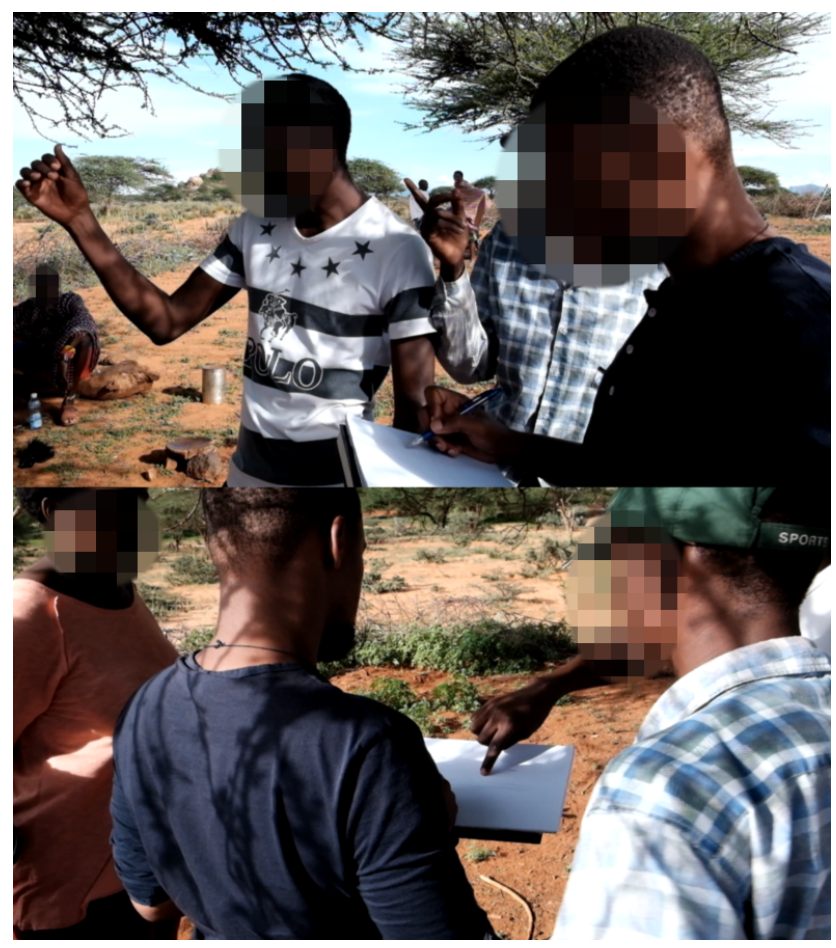

Figure 3. CCC workshop in Longopito: drawing landscapes of anticipation.

\subsection{Methodological outline}

In defiance of the apparent paradox faced by research attempting to study the future by looking at what is present, there are several approaches to future or social foresight methods. In this brief review of these approaches, we exclude predictive studies used for example in meteorological or climate models, election polling, Delphi, game-theoretical methods, conflict or epidemiological scenario development, and similar endeavours that assume the future as a natural fact. The variety of solutions to the paradox mentioned above is still daunting, even when limiting the scope to those methodologies that regard the future as a cultural fact, i.e. as something that is produced through (more-than-)human interactions rather than something that exists independently of future-making practices. As we are not aware of any comprehensive reviews of methodological approaches to studying futures understood as a cultural fact, the following summary might be fragmentary but hopefully sufficient to place this article in the relevant academic literature.

There are many different entry points and angles through which the future is engaged with, which differ ontologically and epistemologically. In want of an established denotation, we refer to approaches that study futures as cultural facts (as opposed to natural facts) as "social foresight methods" (see Kelliher and Byrne, 2015). To make sense of the plethora of social foresight methods, we suggest roughly sorting them according to their respective object of investi- 


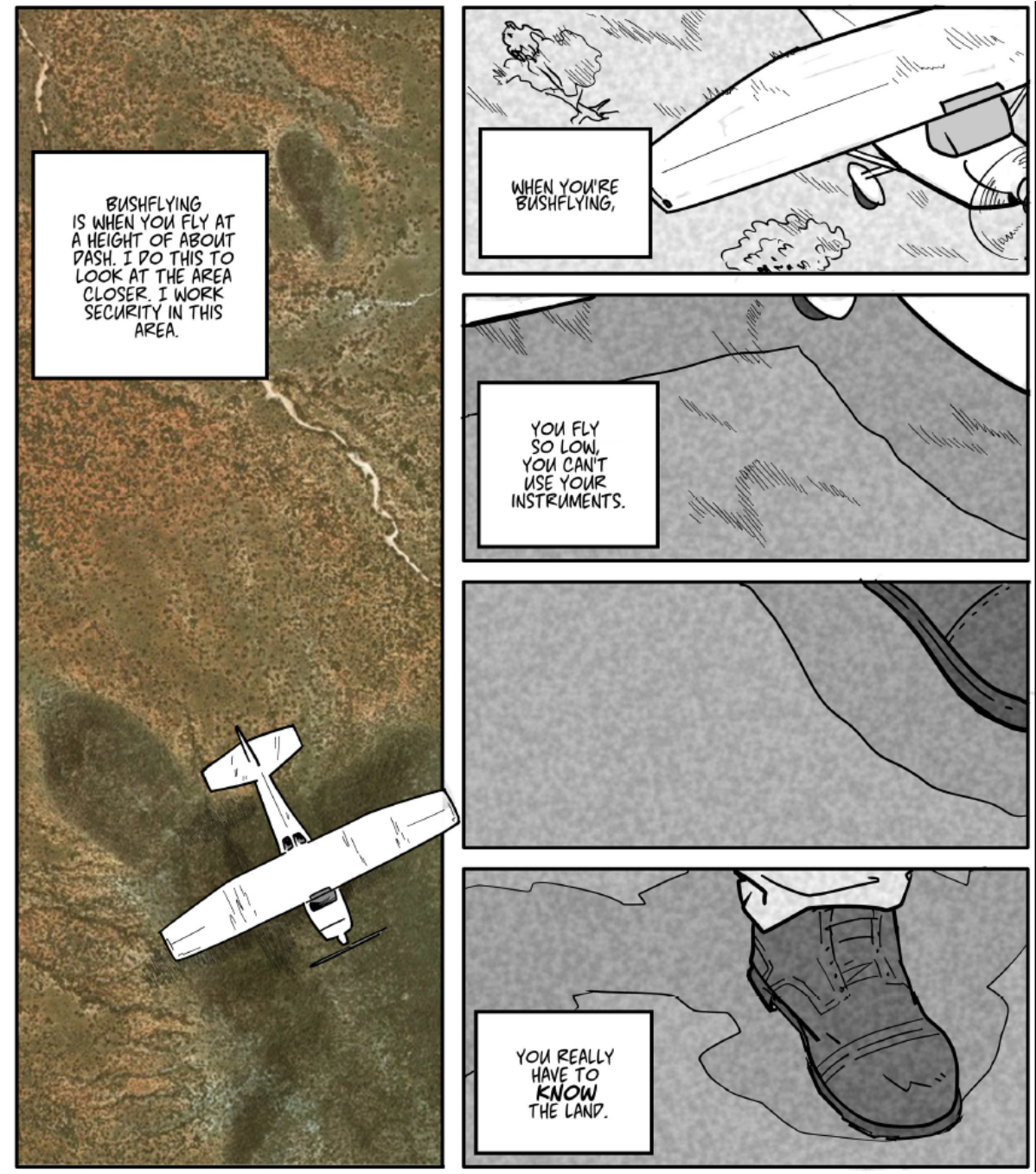

Figure 4. From a "bird's-eye perspective" to "feet on the ground".

gation, which implies different epistemological assumptions. Without claiming completeness, we suggest that most social foresight methods fall into one of the following categories: methods that revolve around the study of (a) emotions and affects, (b) artefacts, (c) images and other visual expressions, (d) narratives and other linguistic expressions, and (e) practices.

Emotions constitute an intuitive way of researching the future in the present, as they correspond to the way people engage with the future in their everyday life through, for example, anxiety and hope. Emotions thus constitute a bridge between the present and the future and therefore constitute a robust epistemology accessing the drawing of timelines mentioned in the previous section. As a "politics of temporality and affect" (Adams et al., 2009:246) anticipation draws lines between the past, present, and future, and Sarah Ahmed argues that "hope is a feeling that is present ... but is directed toward an object that is not yet present" (Ahmed, 2011:173).
Similarly, Miyazaki's uses "the method of hope" (Miyazaki, 2004) and dreams (Miyazaki, 2006) as an entry point to studying knowledge formations and critiques of capitalism. The "capacity to aspire" introduced by Appadurai (2004) similarly involves the delineation of the "horizons of hope and desire" (Appadurai, 2004:75). Even though Appadurai does not explicate a concrete methodological approach, his framing of aspiration in terms of equality justifies a methodological interest in studying how the future is felt in the present.

Artefacts are a less intuitive form of foresight methodology, as one could argue that they constitute witnesses of the past rather than of the future. However, if the entangling of past and future described in the previous section is taken seriously, considering structures and objects as witnesses of the future becomes conceivable. As such, artefacts can function as boundary objects (Star and Griesemer, 1989; Zurba and 
Berkes, 2014) between memories of the past, future expectation, and the current situation.

Infrastructures in particular imply certain promises about the future (Appel et al., 2018); they are enchanted by notions of uncertain futures (Harvey and Knox, 2012). Ruined, failed, or unfinished projects reveal ambivalent temporalities. Harvey and Knox (2012) describe an abandoned bridge as a place where "people speculate on the pasts that could have been and the futures which might have come their way". Similarly, Carse and Kneas (2019) focus on "Unbuilt and Unfinished" infrastructures as a site of ambivalently entangled temporalities: shadow histories that might have been, nostalgic futures that recall past anticipations, or zombies of shelved projects that only exist in a form of spectral potential. The previous section described how infrastructures are implied not only in the structuring of movements through space but also in the creation of temporalities. Methodologically, this implies that this connection should be investigated through questions such as, what mobilities are infrastructures anticipated to engender in future, and how are notions of modernity related to "infrastructured" mobilities?

Outside of the realm of infrastructure studies, design futures encompass methodologies that attempt to make the future tangible through the development of artefacts that are both hypothetical and concrete (Angheloiu et al., 2020), such as in Kelliher and Byrne (2015), who describe the results of a workshop where sculptures were produced to depict potential cataclysmic futures. Furthermore, Kelliher and Byrne (2015), and design futures in general, work with the "image of the future" (Polak, 1973), not only as ideational imagination but also in terms of material depictions. In that regard, design futures often emphasise collaborative artistic practices (Kelliher and Byrne, 2015). For example, Johansson and Isgren (2017) used collaborative painting workshops to create visual images of how people remembered the past and anticipated future land-use changes in Tanzania. Their study illustrates how the literal drawing of lines on paper can be used as a methodological entry point to understanding people's imaginations of possible futures.

Other foresight approaches concentrate on the coconstruction of verbal narratives. Sools (2020), for example, uses an exercise in which participants write letters from the perspective of their own future self to an imagined currentday audience. This particular exercise overlaps with other "objects of investigation" as it illustrated an unequal capacity to imagine the future (see Appadurai, 2004) and the importance of hope and other emotional responses to foresight. Other linguistic approaches focus on the "language of futurity" (Mendieta, 2020:241), maintaining that the "future is constructed by language" (Inayatullah, 1990:134) and therefore implies discursive power relations. In that regard, Mendita (2020) examines how language, as well as mobile practices, is employed in the creation of colonial imaginaries of the future, as well as in their deconstruction.
Practices are another entry point for many social foresight methods. Ringel (2012) explores how anarchist practices have the potential to resist dominant temporalities. On a similar note, Anderson (2010) investigates "practices that render specific futures present", and Kleist and Jansen (2016) combine the aforementioned emotional futurity of hope with attention to practices of (im)mobility, reflecting the conceptual argument about a spatio-temporal overlap delineated above: lines of movement entangle with timelines.

While the emphasis of these approaches differs, most social foresight methods attend to more than one way of engaging futures. The method we introduce in this article is accordingly meant as a synthesis of all of the above-listed approaches: it aims at achieving an effective engagement with future imaginations of infrastructural (im)mobilities through the collaborative production of visual narratives which are eventually compiled into a publication (i.e. a comic book as an artefact). As both artefact and praxis, these collaborative comic books are not only expressions of pre-existing imaginaries of the future. Similar to Tim Ingold's notion of incorporation (Ingold, 2000:193 ff.), not only is drawing lines a gesture that inscribes an idea into matter, but also these imaginations "arise within the current of the involved activity" (Ingold, 2011a:10). Epistemologically, collaborative comic creation recognises all three types of lines introduced in the previous section: the collaborative drawing of story-lines in a comic book makes imagined timelines visible that would otherwise be occluded by the corridor masterplans (MüllerMahn, 2019:2) of the LCDA.

The use of comics in academic research is not new, even though they are mostly regarded either as an object of study or as a means of communicating research. Comic books have graduated from "pulp fiction" to a serious art form that is increasingly recognised by academics as a way to communicate complex content in an accessible way (Amstrong, 2013). Their potential to communicate research (Brantner and Lobinger, 2014) or development policies (Packalen and Sharma, 2007) is recognised in an increasing body of scientific literature, notably in the field of medical science (Al-Jawad, 2015; Green, 2013). In addition to their function as a communication tool, Al-Jawad (2015) stresses that comics also provide a unique methodology and productive way of thinking about her work. The London-based non-profit organisation PositiveNegatives not only incorporates comics into its ethnographic methodology but also stresses the importance of the consultation and participation of interlocutors (PositiveNegatives, 2020). Several studies are based on comics that PositiveNegatives has produced about, for example, the stories of refugees and other marginalised people. Very similarly to what we suggest in this paper, Davies (2019) discusses how these comics constitute "counter-geographies" and argues that comics braid together space and time, as well as the past and the present.

While the approach, conceptualisation, and ambition to make marginalised "counter-geographies" visible is very 
similar to CCC, the methodology we suggest here diverges in two subtle but important aspects. First, we primarily focus on the process of making the comic rather than on the final product. While the comics are very useful to illustrate a point, the analytical entry point is provided by ethnographic research of the workshops in which these comics are produced. In this, our method is similar to the claim of AlJawad (2015:371) that "comics are research" and that the "construction of comics" is part of the ethnographic process. Second, we attempt to go beyond participation and consultation (see Arnstein, 1969) and emphasise the importance of collaboration with interlocutors, meaning that they not only give an account but also are directly involved in the drawing of the comics themselves. This aspect is most similar to the "grassroots comics" of Packelen and Sharma (2007), who succeeded to a much higher degree in facilitating participants to produce their own stories with little to no intervention by external illustrators or researchers.

\subsection{Introducing collaborative comic creation}

The method of collaborative comic creation, or CCC for short, has been created in the context of a planned development corridor in Kenya, the Lamu Port-South SudanEthiopia-Transport (LAPSSET) corridor. The aim of the study was to examine the ways people living alongside the corridor were actively engaging with the vision of development and modernity that the LAPSSET project represents, either aligning with the infrastructural vision or altering and even resisting it. As construction work on the ground had not yet started at the time of the fieldwork, the research design had to struggle with the epistemological paradox that social foresight methods face: how can the friction between different futures be researched in the present? The CCC method is meant to answer that question by creating a tangible boundary object (Star and Griesemer, 1989) between past, present, and future. In the following section, we expound the practical implementation of $\mathrm{CCC}$, relate it to the more general conceptual framework, and discuss challenges we faced in each step.

The team that developed and implemented the method was composed of four members: Anne, a Nairobi-based (comic) author and playwright; Dan and Naddya, both illustrators and animators from Nairobi with experience in participatory comic production; and Theo, a geographer based in Berlin. Both Anne and Naddya had extensive experience in the creation of comic stories for and with marginalised communities in Kenya. They had previously mainly focussed on issues affecting young girls in both rural and urban contexts, often addressing sensitive topics such as sexual violence. This previous experience was essential in the planning and implementation of the CCC method, and we suggest that anyone reproducing the method laid out below should try and get people involved in the project who have similarly worked in the area before.
The method was carried out in four distinct steps: (1) a preliminary survey, (2) a series of five workshops, (3) synthesis of the workshop results in five comic strips, and (4) a follow-up survey to get feedback on the comic strips.

\subsection{Preliminary survey}

The preliminary survey was carried out as part of conventional fieldwork, conducted for 2 months in early 2018 by Theo, the researcher, along the planned route of the corridor. The route's course was traversed on foot along the segment between the towns of Isiolo and Kapedo. During that time, 87 semi-structured interviews were carried out, mainly with people living in small settlements close to the route and pastoralists living largely in the areas between settlements. Most of the inhabitants who were interviewed belonged to one of three ethnic groups: Samburu, Pokot, and Turkana. Expert interviews were conducted with local and county government officials, community organisers, and chairs of NGOs in Nairobi, as well as in towns along the researched segment. Most interviews were conducted in English or Swahili or via a translator in one of the local languages.

While the main goal of this fieldwork was the gathering of biographical interview data about memories and expectations of the interviewed inhabits regarding the LAPSSET corridor, a secondary purpose was the pre-selection of five groups or individuals whose stories might be suitable for the collaborative comic workshops. Criteria for this process were varied. One major concern was diversity in terms of age, gender, ethnicity, geographical location, and attitude towards the LAPSSET project. A second unfortunate consideration was security. ${ }^{1}$ Lastly, and perhaps most problematically, the selection was based on the perceived appeal of the story, the charisma of the people who had given the account, and the likelihood that it could be translated into a "tellable" comic. With an eye towards the multiplicity of temporalities mentioned in the conceptual section above, it is important to emphasise that CCC is hardly able to depict the totality of this multiplicity but rather attempts to outline some among many alternative temporalities that are covered by the dominant vision of the future produced by the LCDA.

In most qualitative research, stories are selected by their appeal as stories to some extent, but in this case, the standards were particularly specific and selected for properties that heavily skew the sampling process. While it is not the aim of CCC to create representativeness, the inherent need for a "good story" tends to favour the extraordinary over the every day. A further problem arises when the person who is doing the selection process is from a different cultural background, thus favouring accounts that coincide with their par-

\footnotetext{
${ }^{1}$ During the fieldwork, the researcher came under fire at the conflict-prone border between areas inhabited by Pokot and Turkana. Subsequently, the team decided to omit Turkana County for safety reasons, conflicting with efforts for the highest possible diversity.
} 


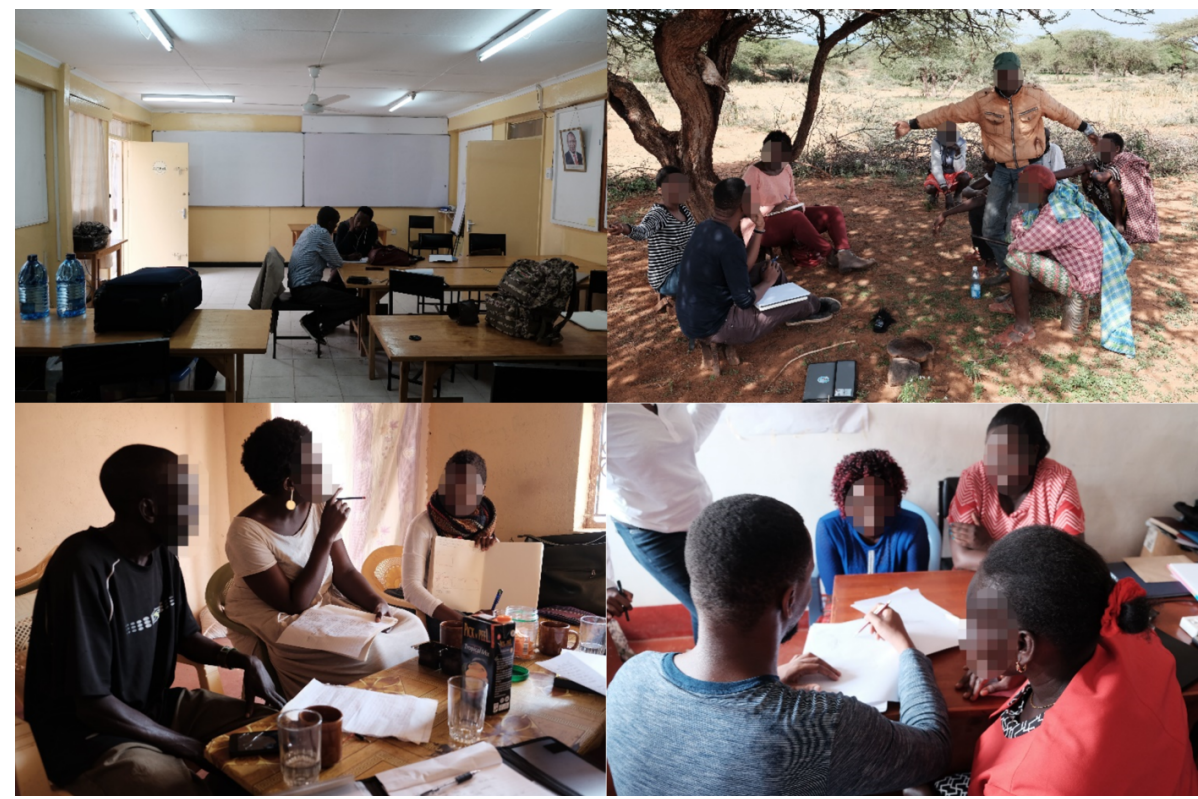

Figure 5. Different workshop situations. Clockwise from top-left: a classroom, a traditional meeting place under an acacia tree, an office space, and a bar.

ticular preferences. In order to moderate this issue, the cases were selected together with three writers and illustrators from Kenya. However, as we will further expound below, the cultural differences between young Kenyans with university degrees from Europe, Canada, and Nairobi and pastoralists in rural areas can be quite significant as well.

\subsection{CCC workshops}

After the planning of an itinerary based on the selected cases, the entire group consisting of two illustrators, one writer, and one researcher embarked on a $5 \mathrm{~d}$ road trip, conducting one CCC workshop per day. The workshops had been planned in advance with the participants, who were asked to schedule ca. $5 \mathrm{~h}$ for the workshop. An appropriate meeting place was essential. At a minimum, it needed to offer sufficient space, a table, and good lighting. Ideally, it would further provide an atmosphere where the participants would feel at ease, as well as a means to keep outside interruptions to a minimum. Places meeting all of these requirements were difficult but not impossible to find, even though some compromises had to be made (Fig. 5). In each location, we provided drawing equipment, as well as snacks and refreshments.

The workshop itself followed roughly the same scheme, independent of its respective location. After introductions, we started with a general interview, which focussed on biographical details of the person, which often went far beyond the immediate concern of the LAPSSET corridor. Here, Anne (the author) as well as the two illustrators Naddya and Dan moderated the discussion, while Theo (the researcher) remained in the background but was available in case spe- cific questions came up. This step often took 1 to $2 \mathrm{~h}$, as in the specific context in which we conducted the interviews, it is common to invest time in introductions and "settling in" as doing otherwise would put people off. In a second step, the workshop focussed on the comic story itself, discussing plot points within the story, rough sketches of the comic's layout, or visual details such as the style of the dress a participant had worn on a particular day (Fig. 6).

In part two, participants were able to engage in the process of drawing comics more actively, while the researcher remained in the background as an observer. The researcher would note what topics and scenes seemed to be particularly important for the participant(s), which situations they described in detail, and which they skipped over. This was particularly useful for opening up a way to talk about how people felt during particular situations. While it is difficult for some to answer direct questions such as "so how did that make you feel?", descriptions or sketches of facial expressions, postures, and constellations of people in a scene can be quite helpful to substantiate discussions about sometimes abstract emotions. In this step, Anne moderated most of the general discussions, while Naddya and Dan worked with individual workshop participants on the drawings. This set-up was especially useful with groups, where individual members or smaller groups could work out particular details with the illustrators in small breakout sessions. However, it also made it more difficult for the observing researcher, as his attention was split among two or three smaller groups.

Even though we encouraged everyone to draw as much as possible, some participants preferred to give the illustrators instructions on how to depict certain situations, while 


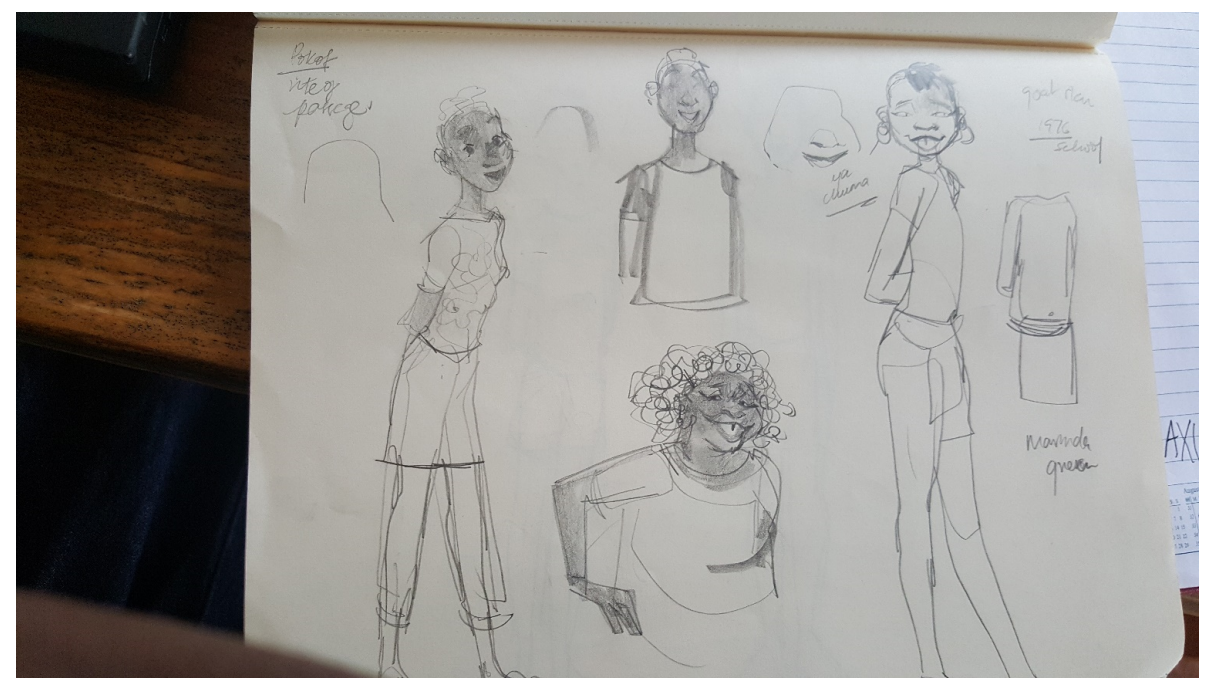

Figure 6. Sketches during the workshop depicting the workshop participant in a "modern" dress (left) and traditional attire (right).

others took the pencil and started drawing scenes or particular details themselves (Fig. 7). As the name suggests, collaborative drawing is one of the cornerstones of the CCC methodology and proved to be highly insightful, in terms of not only how participants depicted particular details but also what details they chose to focus on. However, this participation proved to be problematic as well. Even though most people were familiar with comic books, none of them was well acquainted with the particular demands that drawing a comic entails. Many participants felt intimidated by the prospect of drawing together with "real" artists and preferred to describe scenes rather than to draw them. As a consequence, our author (Anne) who herself describes her artistic talents as non-existent, moderated the drawing, in order to show participants that it was alright if their drawings were not perfect: "See what I'm drawing [all laugh]? I ... So if you draw, you can't do worse than me" (workshop, 6 April 2018, translated from Swahili by the authors). While this strategy partly succeeded, the collaborative aspect of the comic production was limited to single pictures as opposed to entire panel sequences. In hindsight, it might have been useful to use a very simple pre-defined panel layout for each page, exchanging flexibility for simplicity. The major problem was probably the limited timeframe, in which it was not possible to teach participants the necessary knowledge and skill to produce entire comic stories. In contrast, the grassroots comics of Packalen and Sharma (2007) were produced over a period of usually $3 \mathrm{~d}$, which would not have been feasible for us due to a limited budget. ${ }^{2}$

\footnotetext{
${ }^{2}$ Packalen and Sharma (2007:155) operated with a budget of ca. EUR 10000 per workshop, while we spent about $20 \%$ of that amount for five workshops.
}

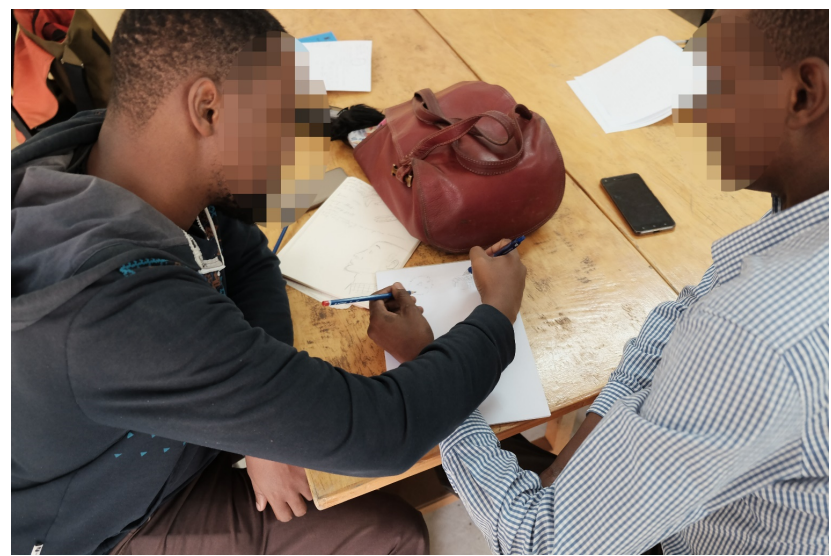

Figure 7. Illustrator (left) and workshop participant (right) drawing a traditional Samburu hut together.

In some cases, the entire group would take a short tour to visit the surrounding area in which the story took place. This was particularly relevant for one workshop conducted with a group of Samburu herders, who demonstrated how they would usually navigate the area and communicate with the animals. As we will show in the next section, one major concern regarding the future developments engendered by the LAPSSET corridor related to changed mobility practices, in terms of either anticipated disruption of migration routes or displacement. Walking with workshop participants and making sketches of the landscape and people in motion therefore proved to be an expedient addition to the sedentary workshop situation around a table. 


\subsection{Synthesis and final artwork}

After the workshop series was wrapped up, the two illustrators Naddya and Dan continued their work on the comic strips based on the sketches and notes that were collected during the workshop, producing five stories of three to five pages each. The procedure followed the conventional procedure of comic production, i.e. a development starting with a script (similar to one for a screenplay), going to a storyboard (a rough sketch of what happens in each panel), to the final artwork, and finally to lettering in both English and Swahili. Naddya and Dan tried to incorporate as many visual and story elements from the workshops as possible (Fig. 9) and used sketches and photos they had taken during phase 3 as references. However, this meant that Anne sometimes had to adapt the accounts of workshop participants to produce "tellable" stories. In other cases, such as Abdi's poem discussed in more depth below, participants determined the narrative of the comic more actively and the workshop was mainly concerned with finding appropriate illustrations.

This active involvement of the artists was necessary because the workshops had not resulted in complete comic strips but rather a collection of images, plot points, and short sequences of panels. We had originally planned that the postproduction of the comics would be minimal, merely consisting of a fine drawing of comics produced during the workshop. However, for the above-mentioned reasons - mainly because of the limited timeframe for each workshop - this was not possible, creating further problems of representation and uneven power relations in the production of the final artwork. First, differences in visual idiosyncrasies between the illustrators and workshop participants were more pronounced than expected, even though Naddya had prior experience in working in different cultural contexts. Second, many of the collaborative sketches worked as stand-alone drawings but not in the context of a comic. This meant that many elements had to be changed and adapted by artists in post-production to satisfy the demands of the medium. For this reason, we suggest to base the analysis not solely on the comic stories themselves but mainly on the process of creating them. Lastly, some of the topics that were discussed during the workshop were highly sensitive. One participant, for example, expressed hopes that the LAPSSET would bring a level of connectivity that would prevent the isolation and violence she had experienced as a young woman at the hands of her husband. We did not dwell on these traumatic experiences during the workshop, but nevertheless it was important for the participant that they were part of her story. The artists therefore had to find a way to depict these traumatic experiences sensitively and in consultation with the workshop participant (Fig. 8).

\subsection{Follow-up survey}

In order to alleviate the problem of too much influence on the depictions exerted by the illustrators, the final product, a compendium containing all five comic stories, was distributed along the same segment of the corridor route where workshops had been organised. Feedback and comments from workshop participants and other inhabitants of the area were obtained to be subsequently used to improve the comics. Thirty interviews were conducted following a defined structure, inquiring about pre-existing knowledge about the LAPSSET corridor and asking for opinions and suggestions regarding the content, structure, and visuals of the comic.

The feedback was largely positive, commending the objective of the comic book, the fact that people in the area had been involved in its production, and the fact that the final product was shared. However, the style of the comic was sometimes criticised as too inaccessible: "This is art, not a comic book!", said one respondent and did not mean it as a compliment. Others suggested more colour and a more naturalistic drawing style. One respondent, a participant of one of the workshops, was particularly unimpressed. "This story is about me!", she exclaimed. "It shouldn't be about me; it should be about the people here in the area, and their livestock, the environment". This shows how the particular demands of a "good" comic story - i.e. the need to focus on one protagonist - can clash with the imaginations and wishes of the workshop participants. The story was subsequently altered in order to be more in line with how the participant imagined her story (Fig. 10).

\section{Carto(on)graphy of the future}

In this part, we introduce one of the cases in more detail and discuss how the CCC methodology is able to tease out ways of imagining the future. The text in this particular comic story was written entirely by the workshop participant $\mathrm{Abdi}^{3}$, a poet, teacher, and playwright living in a small town, which is expected to be passed by the LAPSSET corridor. It consists of a poem that he wrote especially for the occasion.

We meet him in a small pub, the Comfort Zone, where he and his friends spend most evenings (Fig. 5, bottom left). Abdi tells us about living in Oldonyiro, a town in the westernmost part of Isiolo's "Scorpion's Tail”, the last settlement before the vast "white highlands" (conservancies and rangelands that are mostly owned and managed by white Kenyans, descendants of British colonisers) stretch out to the west. We talk about him feeling like an outsider - not only for being one of the few Turkana in an area predominantly inhabited by Samburu but also for trying to change his community for the better through poetry. "We Turkana", he says, "no matter where we are going, we are always a minority".

\footnotetext{
${ }^{3}$ Name changed.
} 

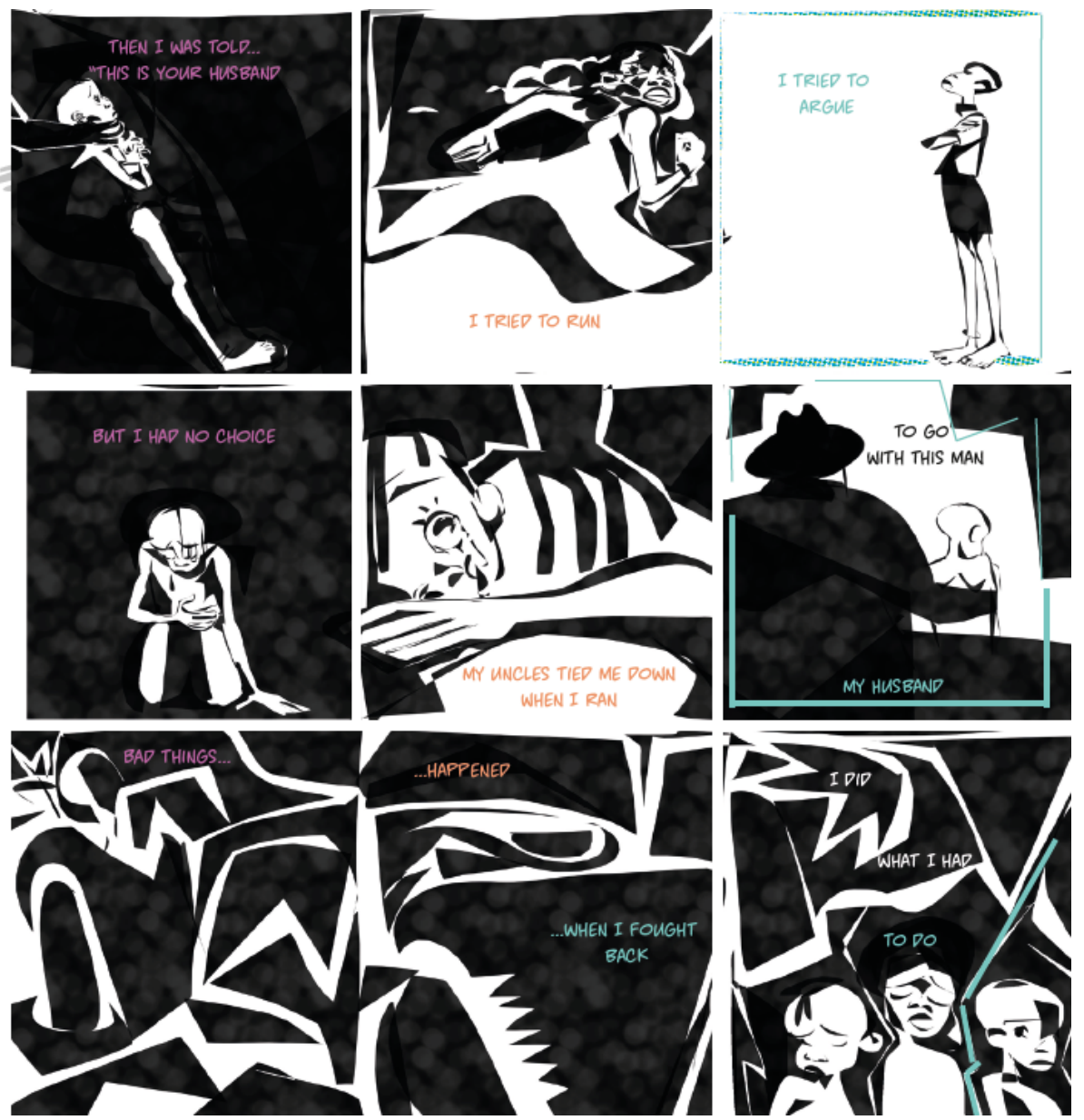

Figure 8. Excerpt from one of the collaborative comics. How should the "bad things" be drawn?
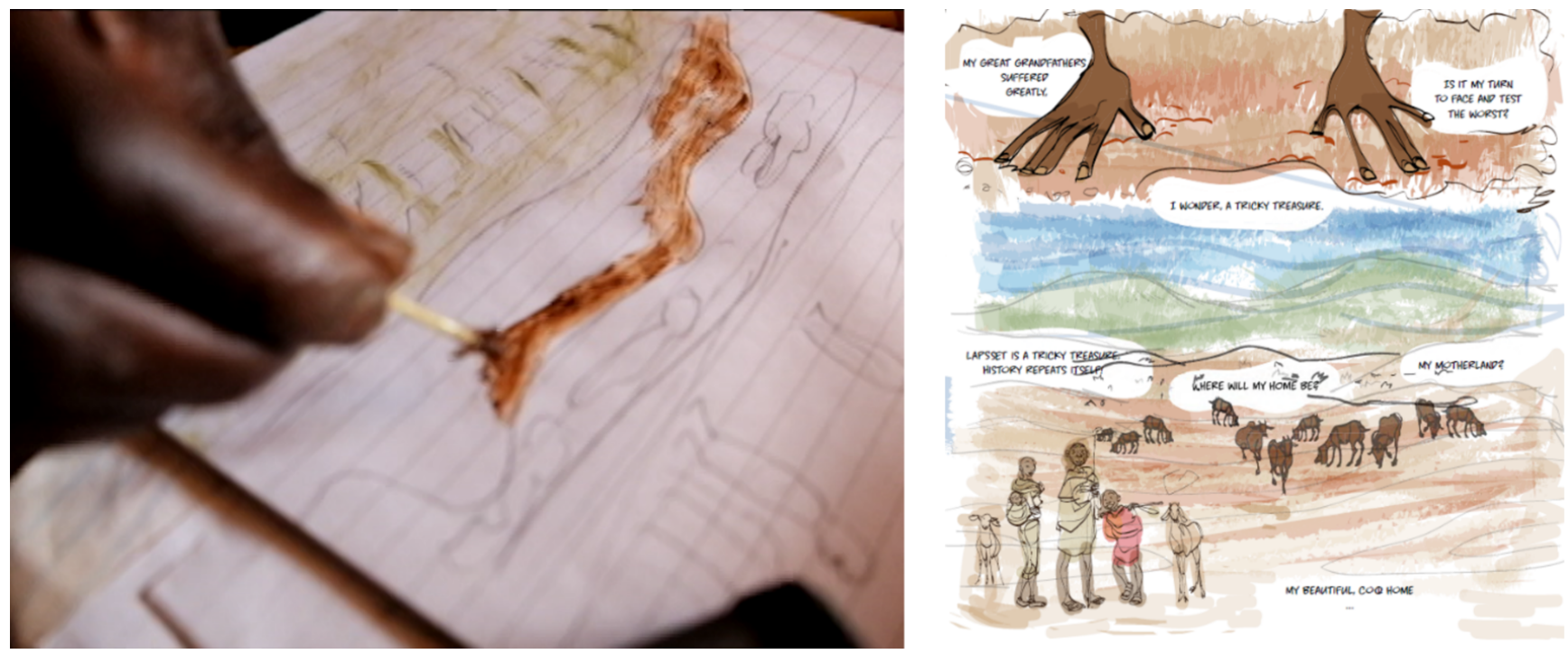

Figure 9. Left: a workshop participant suggests using soil and leaves to draw landscape and flora. Right: illustrator's rendering of the scene based on the participant's sketch. 

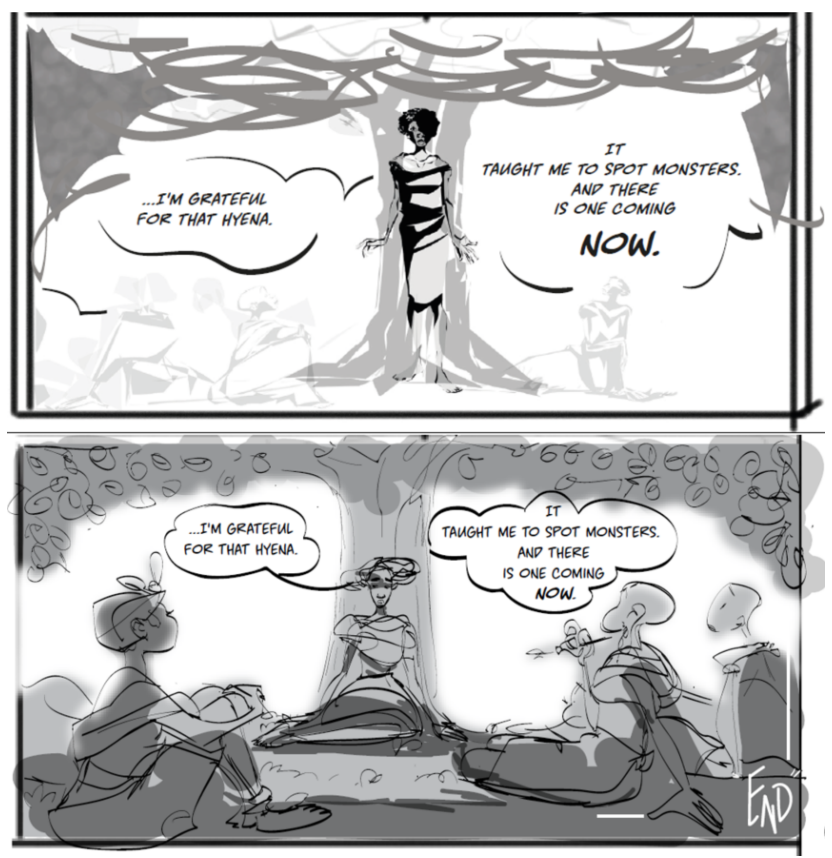

Figure 10. Two versions of the same scene. Top: the protagonist is the centre of the story (first version). Bottom: after feedback from the workshop participant, the protagonist is depicted as part of a community (second version).

The first stanza of his poem "Tricky Treasure" and subsequently the text of the first few panels reads as follows: "I woke early in the morning, // Joyful and grateful. // The walls filled with posters, // LAPSSET is the future!... // I wondered, a tricky treasure" (Fig. 11). He suggests drawing this scene quite literally: him standing in front of a giant signboard promising a way forward while simultaneously blocking his way. In content if not in size, it is similar to the LAPSSET information material and newsletters ${ }^{4}$ that can be found at the chief's office a couple of houses up the road from where we sit. The issue the researcher had seen during his preliminary survey for example claims that "the LAPSSET Corridor Program is one of the flagship Vision 2030 projects intended to spur economic development by creating new opportunities and unlocking the latent economic potential in the larger hinterland of Northern and North Eastern and Western parts of Kenya" (LCDA, 2017:2). Next to it, the glossy brochure depicts a GIS-rendered map of the corridor's growth areas and a picture of a group of 20 smiling, potbellied men and 2 women. The future, it seems, is so bright that most of them have to wear sunglasses.

While the illustrators naturally tended to focus on drawing Abdi and the signboard, he was more concerned with the

\footnotetext{
${ }^{4}$ For examples of the newsletters that are delivered not quite regularly to the chief of each location along the route of the LAPSSET corridor, visit http://www.lapsset.go.ke/newsletters/ (last access: 29 November 2020).
}

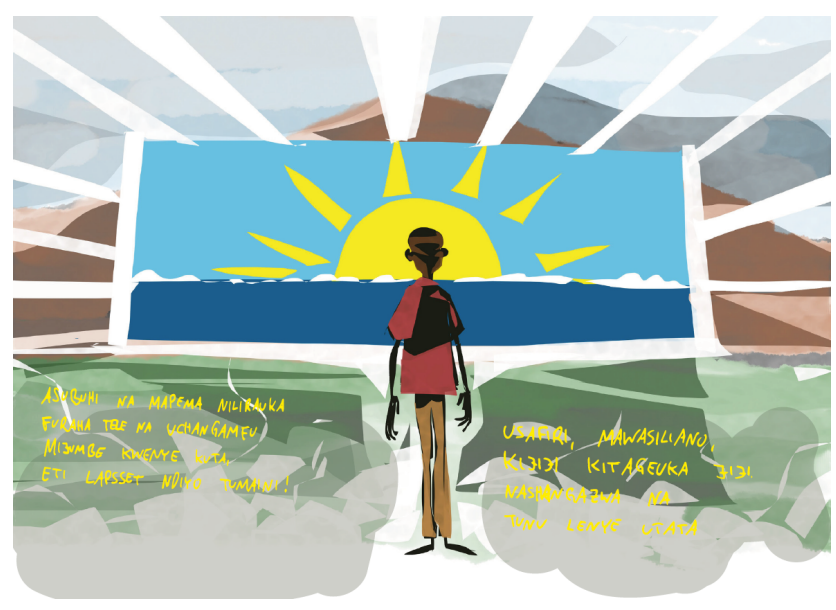

Figure 11. The first page of "Tricky Treasure", depicting Abdi standing in front of a giant LAPSSET poster blocking his way.

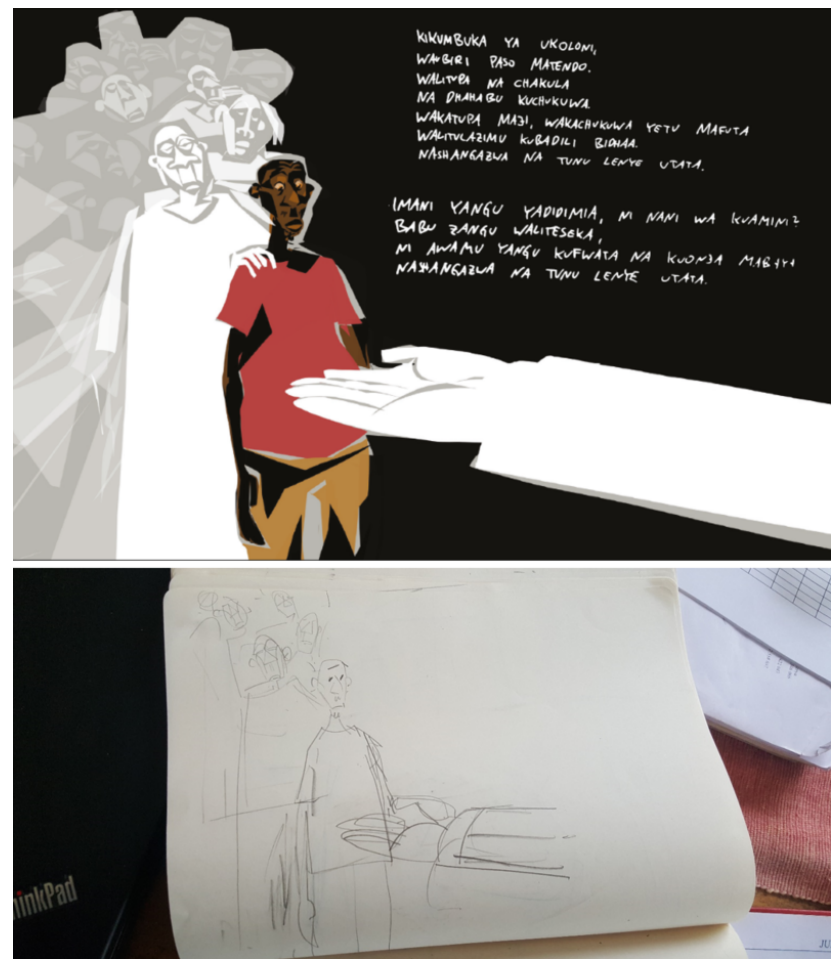

Figure 12. Extract from Abdi's comic strip. He is faced with the same "tricky treasure" as generations before him. Below: the sketch of the scene made during the workshop.

surrounding environment. The hills, he suggested, should be dried up and barren, contrasting with the beautiful image on the poster. The promise of the LAPSSET would be enticing but at the same time suspicious - could the future really be this bright if the present holds that much hardship? How could he possibly trust the promises of the glossy brochure in the chief's office - how could he possibly not wonder if they might be true after all? 
This suspect promise - or Tunu Lenya Utata ${ }^{5}$ as the poem's title in Swahili reads - is the central concern for Abdi. The contrast between the bright future promised by the corridor and the often-difficult reality he and others face every day is for him symbolic of many other contradictions that the infrastructure project implies. The next stanza reads, "Transportation, telecommunication // our village changing to a city // I wonder, a tricky treasure". On the one hand, improved transportation and telecommunication are certainly beneficial; on the other hand, Abdi worries that the local culture might be paved over in future. "Let me show you something" he says at this point. Realising that the grey pencils and brightly coloured markers will not do, he goes outside and collects some leaves, twigs, and soil from the ground. Explaining how he uses this technique to teach his pupils how people in the area used to draw pictures before the arrival of the Europeans ${ }^{6}$, he chews on a twig until it fringes and bristles develop. He then mixes the soil with some water and starts painting a landscape (Fig. 9). For trees and shrubs he uses rolled-up leaves.

The contrast between the glossy pages in the newsletter or the poster Abdi's comic persona encounters in the first panel and this image rendered in soil and leafy smudges could not be more drastic. On one page are straight, computergenerated lines of a map depicting the "national perspective" and an unequivocally bright future. On the other page are muddy lines, soil depicting soil, and leaves depicting leaves: an image that leaves plenty of space for tautologies and paradoxes. They express the uncertain ambivalence that Abdi feels in relation to the future, a tricky treasure indeed. It is in this way that collaborative comics can provide a critical counter-cartography. To a small extent, they are able to represent invisible and marginalised imaginations of the future that challenge the otherwise monopolistic images provided by the LCDA.

Another way Abdi's comic strip diverges from the dominant imagination of a future at the LAPSSET corridor is its unique conscription of history (see Latour, 1992:257). The LAPSSET corridor as depicted by the government is not ahistorical. For example, a video played in Tullow Oil information centres in Turkana depicts a computer-animated map of the colonial Uganda Railway while proclaiming, "And just as the transport sector - the old railway over a hundred years ago - opened up Kenya's only development corridor that has been the anchor of Kenya's development, the new oil and gas industry represents our opportunity to open up Northern Kenya for expansion and development" (Project Oil Kenya, 2018, timestamp $1 \min 45 \mathrm{~s}$ ). The timeline thus created describes a resumption of a process defined by continuous progress along the path of development - a word that

\footnotetext{
${ }^{5}$ Tunu translates to "a thing or present of value", while lenye utata could be translated as being complex and debateable.

${ }^{6}$ We have no proof if this is actually true, but in this case, Abdi's reasoning matters more than the actual circumstances.
}

appears three times in this one sentence. The LAPSSET constitutes a "Game Changer Infrastructure", as the footer on every single page of the "Integrated Transport Infrastructure Master Plan For Lamu Port City" (LCDA, 2018) proclaims. The LCDA builds the LAPSSET corridor as a historic event (Lundborg, 2012), a game changer that clearly defines history in terms of before and after the LAPSSET; it is not only a straight road and pipeline for cars and oil to travel along but also a straight path through history.

The timeline Abdi draws in his comic is different, in that he does not see a continuation along a path but a repetition of past injustices. "My great-grandfathers suffered greatly, // Is it my turn to face and test the worst?" (Fig. 12), he writes, "LAPSSET is a tricky treasure, // History repeats itself! // Where will my home be?" It is not the historic event that the LCDA creates through talk of "Game Changer Infrastructure" but a "pure" event in the sense Lundborg (2012) describes it. Abdi's engagement with the absent presence of the LAPSSET corridor escapes into the past and the future at once: the LAPSSET is what had happened to his grandfathers and will happen to him but is not happening now. The ambivalence and "trickiness" of the LAPSSET is due to this intangibility of its meaning in the present moment. Projecting this tricky image onto a piece of paper is how the CCC method attempts to present LAPSSET's absence.

Thinking about how to illustrate this scene, we talk a lot about Abdi's ancestors: what garments they would have worn and the stools they would have sat on. The illustrators condense this into a picture showing Abdi facing the same test of the "tricky treasure" as generations before him, who are depicted as ghostly figures behind his back, gone but present in his mind as he contemplates the asserted future benefit of the LAPSSET corridor. What promises mobility along the corridor for some threatens expulsion away from it for others and as history repeats itself, Abdi does not see himself in the former group. As he said in an interview during the preliminary survey, "My hopes for the future? Right now, even my hopes are diminished". Fearing a repetition of the colonial past, there is no future.

These too are lines crossing and opposing those drawn by the LCDA. The comic depicts an alternative timeline: one that does not follow the one straight, tarmacked path of "development" of the historic event but the erratic movements of the pure event, which meanders, bends back on itself, loops, and repeats. Instead of a clear goal - from the drill-site to the harbour, from underdevelopment to modernity - there is again ambivalence and uncertainty: "Where will my home be?" In our opinion, this is the most important aspect of social foresight methods: the ability to express the trickiness, the tunu lenye utata, of facing many doubtful futures, opposing the bold certainty of the one straight line along the LAPSSET towards modernity expressed by the corridor masterplan. 


\section{Conclusion}

What this article describes is less a fully fledged method and more a sketch of a possible way of studying imaginations of futures that are marginalised by dominant visions of the future. We do however believe that this first attempt can be further developed, generalised, and adapted to different contexts. The particular approach presented in this article emphasises an engagement with the dreamscapes of modernity (Jasanoff and Kim, 2015) created by a development corridor in Kenya and the opposing imaginations of the future by the local population. We believe that critical social foresight methods are particularly relevant in this context, as they have the potential to breast dominant future imaginaries and thus not only are useful as a tool of knowledge acquisition but also could be applied in explicitly emancipatory action research. This potential has not been fully explored in this study, but we suggest further research could investigate, elaborate, and utilise this aspect of the CCC method.

We have argued that collaborative comics constitute a valuable addition to social foresight methods as they combine different existing approaches, paying attention to emotions, artefacts, images, stories, and practices. Here, the word "drawing" reveals a useful double meaning as both noun and verb. This double meaning reflects Tim Ingold's discussion (Ingold, 2000:193 ff.) of the difference between inscription and incorporation, i.e. an understanding of human work as the premeditated translation of thought into matter or conversely as the concurrent and mutual development of understanding and work. As an artefact, the collaborative comics constitute inscriptions of ideas about the future in the drawings of a comic book; as practices, they express how the incorporation of drawing comics is actively involved in the production of future imaginations.

Secondly, we contribute to the existing body of social foresight methodology by emphasising the importance of "backsight" in the study of future imaginations. The importance of considering memory and historicity in the creation of future imagination has been acknowledged particularly in the literature on infrastructural technologies (e.g. Appel et al., 2018; Carse and Kneas, 2019; Dalakoglou and Harvey, 2012; Larkin, 2018). The consequences of this insight, however, have not been incorporated into many social foresight methods (a notable exception is Johansson and Isgren, 2017). With the CCC method, we suggested following the life stories of workshop participants, to trace how biography, memory, and history are enlisted to make sense of the present and the future.

Thirdly, we have shown the importance of spatiality in the imagination of futures and have described the creation of comic stories as a mapping praxis. Figures $2-4$ exemplify the importance of mapping during the workshops that shifts between embedded surveying of the landscape and imagined bird's-eye perspectives. These comics are quite literally a map of time (Dittmer, 2010:222), both within the logic of the comic book where spatial and temporal progression converge and in the logic of future imaginaries that are expressed through anticipations of future landscapes. These landscapes, in turn, are characterised by the mobilities they afford or prohibit: Abdi speaks not only of displacement as a result of the development corridor but also of the advantages of "transportation and telecommunication". Yet others speak of the fences that would constitute obstacles for pastoral mobilities. More so than many other media, we have argued that comic books are particularly suitable to embracing the entanglement of timelines and lines through space, as this is an integral part of how they convey meaning. In that, comics are similar to transport infrastructures, as these too create a particular vision of the future and what it means to be modern by the construction of lines (roads, pipelines, cables) through space. Comics, therefore, have the potential to counter the specific time-space arrangement of infrastructures by visualising alternative ways of braiding together different geographies and histories.

Lastly, the above-listed points make apparent the need for a theoretical grounding of social foresight methods such as CCC. In this article, we have only sketched an outline of such conceptualisation, but we believe that it provides a useful basis upon which further development of the method is possible both conceptually and practically. The simultaneous consideration of different types of lines - spatial, temporal, and graphic - allows for appreciating many different dimensions of future making: how they involve the past as much as the future, practices (such as mobility), images, emotions, objects, and infrastructures. As Abdi's comic has illustrated, these different dimensions do not form a single coherent picture of the future but instead one that is ambivalent, uncertain, and full of tricky treasure. That is, however, precisely the point.

Data availability. The comics can be accessed under the DOI https://doi.org/10.13140/RG.2.2.30864.97289 (Aalders et al., 2018) as well as via the link https://www.researchgate.net/publication/ 340789302_Hadithi_za_LAPSSET_Collaborative_Comics (last access: 1 December 2020) (Aalders et al., 2018).

Author contributions. NAOO and DM contributed to the article in terms of its methodology and investigation process. They furthermore created visualizations, i.e. the illustrations of the collaborative comics. AM also contributed to the methodology and investigation, as well as the writing process (review and editing). TA contributed to the conceptualization, as well as funding acquisition, investigation, methodology, supervision, and writing (original draft and preparation).

Competing interests. The authors declare that they have no conflict of interest. 
Acknowledgements. We like to thank everyone who participated in the collaborative comic creation workshops.

Financial support. The research project was partially funded by Riksbankens Jubileumsfond (Sweden) through the "Communication Projects" programme.

Review statement. This paper was edited by Antje Schlottmann and reviewed by two anonymous referees.

\section{References}

Aalders, J. T.: Building on the Ruins of Empire: The Uganda Railway and the LAPSSET Corridor in Kenya, Third World Q., https://doi.org/10.1080/01436597.2020.1741345, 2020.

Aalders, J. T., Moraa, A., Muli, D., and Oluoch-Olunya, N. A.: Hadithi Za LAPSSET [Comic], Nairobi, https://doi.org/10.13140/RG.2.2.30864.97289, 2018.

Adams, V., Murphy, M., and Clarke, A.: Anticipation: Technoscience, Life, Affect, Temporality, Subjectivity, 28, 246-265, https://doi.org/10.1057/sub.2009.18, 2009.

Ahmed, S.: Happy Futures, Perhaps, in: Queer Times, Queer Becomings, edited by: McCallum, E. L. and Tuhkanen, M., State University of New York Press, Albany, 159-182, 2011.

Alesina, A., Easterly, W., and Matuszeski, J.: Artificial States, J. Eur. Econ. Assoc., 9, 246-277, https://doi.org/10.1111/j.15424774.2010.01009.x, 2011.

Al-Jawad, M.: Comics are Research: Graphic Narratives as a New Way of Seeing Clinical Practice, J. Med. Humanit., 36, 369-374, https://doi.org/10.1007/s10912-013-9205-0, 2015.

Amstrong, S.: Why academics are taking comic books seriously BBC News, BBC News, available at: http://www.bbc.com/news/ uk-england-24458521 (last access: 22 March 2017), 2013.

Anderson, B.: Preemption, Precaution, Preparedness: Anticipatory Action and Future Geographies, Prog. Hum. Geogr., 34, 777798, https://doi.org/10.1177/0309132510362600, 2010.

Angheloiu, C., Sheldrick, L., and Tennant, M.: Future Tense: Exploring Dissonance in Young People's Images of the Future through Design Futures Methods, Futures, 117, 102527, https://doi.org/10.1016/j.futures.2020.102527, 2020.

Appadurai, A.: The Capacity to Aspire: Culture and the Terms of Recognition, in: Culture and Public Action, edited by: Rao, V. and Walton, M., Stanford University Press, Stanford, 2004.

Appadurai, A.: The Future as Cultural Fact, Essays on the Global Condition, Verso, London, New York, 2013.

Appel, H., Anand, N., and Gupta, A. (Eds.): The Promise of Infrastructure, Duke University Press, Durham, 2018.

Arnstein, S. R.: A Ladder Of Citizen Participation, J. Am. Plan. Assoc., 35, 216-224, https://doi.org/10.1080/01944366908977225, 1969.

Brantner, C. and Lobinger, K.: Campaign Comics: The Use of Comic Books for Strategic Political Communication, Int. J. Commun., 8, 248-274, 2014.

Carse, A. and Kneas, D.: Unbuilt and Unfinished, Environ. Soc., 10, 9-28, https://doi.org/10.3167/ares.2019.100102, 2019.
Cattoor, B. and Perkins, C.: Re-cartographies of landscape: New narratives in architectural atlases, Cartogr. J., 51, 166-178, https://doi.org/10.1179/1743277413Y.0000000076, 2014.

Corner, J.: The Agency of Mapping: Speculation, Critique and Invention, in: The Map Reader, John Wiley \& Sons, Ltd, Chichester, UK, 89-101, 2011.

Coverley, M.: Psychogeography, Pocket Essentials, Harpenden, 2006.

Cowen, D.: The Deadly Life of Logistics - Mapping Violence in Global Trade, University of Minneapolis Press, Minneapolis, London, 2014

Cresswell, T.: On the Move: Mobility in the Modern Western World, Routledge, New York, London, 2004.

Dalakoglou, D. and Harvey, P.: Roads and Anthropology: Ethnographic Perspectives on Space, Time and (Im)Mobility, Mobilities, 7, 459-465, https://doi.org/10.1080/17450101.2012.718426, 2012.

Davies, D.: Braided geographies: bordered forms and cross-border formations in refugee comics, J. Cult. Res., 23, 124-143, https://doi.org/10.1080/14797585.2019.1665892, 2019.

Debord, G.: Society of the Spectacle, Rebel Press, London, 1967.

Dittmer, J.: Comic book visualities: a methodological manifesto on geography, montage and narration, T. Inst. Brit. Geogr., 35, 222 236, 2010.

Edwards, P. N.: Infrastructure and Modernity: Force, Time, and Social Organization in the History of Sociotechnical Systems, in: Modernity and Technology, edited by: Misa, T. J., MIT Press, Cambridge, 185-226, 2003.

Enns, C. and Bersaglio, B.: On the Coloniality of "New" MegaInfrastructure Projects in East Africa, Antipode, 52, 101-123, https://doi.org/10.1111/anti.12582, 2019.

Green, M. J.: Teaching with Comics: A Course for FourthYear Medical Students, J. Med. Humanit., 34, 471-476, https://doi.org/10.1007/s10912-013-9245-5, 2013.

Harley, J. B. and Woodward, D.: The History of Cartography - Cartography in Prehistoric, Ancient, and Medieval Europe and the Mediterranean, University of Chicago Press, Chicago, London, 1987.

Harvey, P. and Knox, H.: The Enchantments of Infrastructure, Mobilities, 7, 521-536, https://doi.org/10.1080/17450101.2012.718935, 2012.

Headrick, D. R.: The Tools of Empire. Technology and European Imperialism in the Nineteenth Century, Oxford University Press, New York, Oxford, 1981.

Inayatullah, S.: Deconstructing and reconstructing the future. Predictive, cultural and critical epistemologies, Futures, 22, 115141, https://doi.org/10.1016/0016-3287(90)90077-U, 1990.

Ingold, T.: The Perception of the Environment, Routledge, London, New York, 2000.

Ingold, T.: Lines: a brief history, Routledge, London, New York, 2007.

Ingold, T.: Being Alive: Essays on Movement, Knowledge and Description, Routledge, Oxon, New York, available at: https://books.google.com/books?hl=de\&lr=\&id= 40yxRsE0OQUC\&pgis=1 (last access: 18 December 2015), 2011a.

Ingold, T. (Ed.): Introduction, in: Redrawing Anthropology: Materials, Movements, Lines, Ashgate, Fernham, Burlington, 1-199, $2011 b$. 
Ingold, T.: The Life of Lines, Routledge, London and New York, 2015.

Jasanoff, S. and Kim, S.-H.: Dreamscapes of Modernity - Sociotechnical Imaginaries and the Fabrication of Power, The University of Chicago Press, Chicago, London, 2015.

Johansson, E. L. and Isgren, E.: Local perceptions of land-use change: using participatory art to reveal direct and indirect socioenvironmental effects of land acquisitions in Kilombero Valley, Tanzania, Ecol. Soc., 22, 3, https://doi.org/10.5751/ES08986-220103, 2017.

Kelliher, A. and Byrne, D.: Design futures in action: Documenting experiential futures for participatory audiences, Futures, 70, 3647, https://doi.org/10.1016/j.futures.2014.12.004, 2015.

Kleist, N. and Jansen, S.: Introduction: Hope over Time - Crisis, Immobility and Future-Making, Hist. Anthropol. Chur., 27, 373392, https://doi.org/10.1080/02757206.2016.1207636, 2016.

Larkin, B.: Promising Forms: The Political Aesthetics of Infrastructure, in: The Promise of Infrastructure, edited by: Appel, H., Anand, N., and Gupta, A., Duke University Press, Durham, 175202, 2018

Latour, B.: Where Are the Missing Masses? The Sociology of a Few Mundane Artifacts, in: Shaping Technology/Building Society - Studies in Sociotechnical Change, edited by: Bijker, W. E. and Law, J., Cambridge, MIT Press, London, 225-258, https://doi.org/10.1007/BF02373670, 1992.

LCDA: The LAPSSET Corridor Projects, LAPSSET Q. Newsl., January-March, available at: https://www.lapsset.go.ke/ newsletters/ (last access: 29 November 2020), 2017.

LCDA: Integrated Transport Infrastructure Master Plan For Lamu Port City, Brussels, available at: https://www.lapsset. go.ke/reports/Lastaccessed:2020-11-29 (last access: 29 November 2020), 2018.

Lundborg, T.: Politics of the Pure Event - Time, Movement, Becoming, Routeledge, London, New York, 2012.

Massey, D.: For Space, SAGE, Los Angeles, London, New Delhi, Singapore, Washington, D.C., 2005.

Mbiti, J. S.: African Religions \& Philosophy, Heinemann, London, 1990.

McCloud, S.: Understanding Comics - the Invisible Art, edited by: Martin, M., Harper Collins, New York, 1993.

Mendieta, E.: Toward a decolonial feminist imaginary: Decolonizing futurity, Crit. Philos. Race, 8, 237-264, https://doi.org/10.5325/critphilrace.8.1-2.0237, 2020.

Miyazaki, H.: The method of hope: anthropology, philosophy, and Fijian knowledge, Stanford University Press, Stanford, 2004.
Miyazaki, H.: Economy of dreams: Hope in global capitalism and its critiques, Cult. Anthropol., 21, 147-172, https://doi.org/10.1525/can.2006.21.2.147, 2006.

Müller-Mahn, D.: Envisioning African Futures: Development corridors as dreamscapes of modernity, Geoforum, 115, 156-159, https://doi.org/10.1016/j.geoforum.2019.05.027, 2019.

Packalen, L. and Sharma, S.: Grassroots Comics: A Development Communication Tool, available at: http://www.worldcomics.fi/ index.php/download_file/view/425/142/ (last access: 29 November 2020), 2007.

Peterle, G.: Comic book cartographies: A cartocentred reading of City of Glass, the graphic novel, Cult. Geogr., 24, 43-68, https://doi.org/10.1177/1474474016643972, 2017.

Polak, F.: The Image of the Future, Elsevier, Amsterdam, London, New York, 1973.

PositiveNegatives: Methodology, available at: https: //positivenegatives.org/about/methodology/, last access: 10 June 2020.

Project Oil Kenya: Project Oil Kenya, YouTube, Kenya, available at: https://www.youtube.com/watch?v=Sd0y2QcFGIg (last access: 29 November 2020), 2018.

Ringel, F.: Towards anarchist futures? Creative presentism, vanguard practices and anthropological hopes, Crit. Anthropol., 32, 173-188, https://doi.org/10.1177/0308275X12437979, 2012.

Sinclaire, I.: Living with Buildings and Walking with Ghosts: On Health and Architecture, Profile Books, London, 2018.

Sools, A.: Back from the future: a narrative approach to study the imagination of personal futures, Int. J. Soc. Res. Methodol., 23, 451-465, https://doi.org/10.1080/13645579.2020.1719617, 2020.

Star, S. L. and Griesemer, J. R.: Institutional Ecology, "Translations" and Boundary Objects: Amateurs and Professionals in Berkeley's Museum of Vertebrate Zoology, 1907-39, Soc. Stud. Sci., 19, 387-420, 1989.

van der Straeten, J. and Hasenöhrl, U.: Connecting the Empire: New Research Perspectives on Infrastructures and the Environment in the (Post)Colonial World, NTM Zeitschrift für Geschichte der Wissenschaften, Tech. und Medizin, 24, 355391, https://doi.org/10.1007/s00048-017-0162-y, 2016.

Varadarajan, S.: Naypyitaw - Dictatorship by cartography, Himal Southasian, 20, 69-71, 2007.

Zurba, M. and Berkes, F.: Caring for country through participatory art: creating a boundary object for communicating Indigenous knowledge and values, Local Environ., 19, 821-836, https://doi.org/10.1080/13549839.2013.792051, 2014. 